\title{
Co-creating and adapting a self-management program for breast cancer survivors integrated in the clinical pathway of breast centers in Switzerland (COSS pilot study).
}

Franziska Schmidt ${ }^{1}$, Karin Ribi ${ }^{1,2}$, Joerg Haslbeck ${ }^{3}$, Corinne Urech ${ }^{4}$, Karin Holm ${ }^{5}$, Manuela Eicher ${ }^{1}-$ On behalf of the COSS pilot study group

1 Institute of Higher Education and Research in Healthcare, University of Lausanne and University Hospital Lausanne, Switzerland; ${ }^{2}$ International Breast Cancer Study Group (IBCSG), Bern, Switzerland; ${ }^{3}$ Swiss Cancer League, Division Follow-up Care, Bern, Switzerland; Institute of Nursing Science, University of Basel, Switzerland;

4 Women's Health Clinic, University Hospital Basel, Switzerland. 5 Patient Advocates for Cancer Research \& Treatment (Association PACRT), Geneva, Switzerland

\section{BACKGROUND}

- The peer-led Cancer Thriving and Surviving Program (CTS) has shown positive effects on depression and stress (Risendal et al., 2014).

The CTS has not yet been adapted for breast cancer nor for Swiss cancer care.

\section{OBJECTIVES}

To culturally adapt the CTS for breast cancer survivors in Switzerland and to define the time point of integration into the clinical pathway.

\section{METHOD}

Transdisciplinary working group: breast cancer survivors, breast care nurses, psycho-oncologists, gynecologist, nursing scientists, oncologists

\section{Workshop 1}

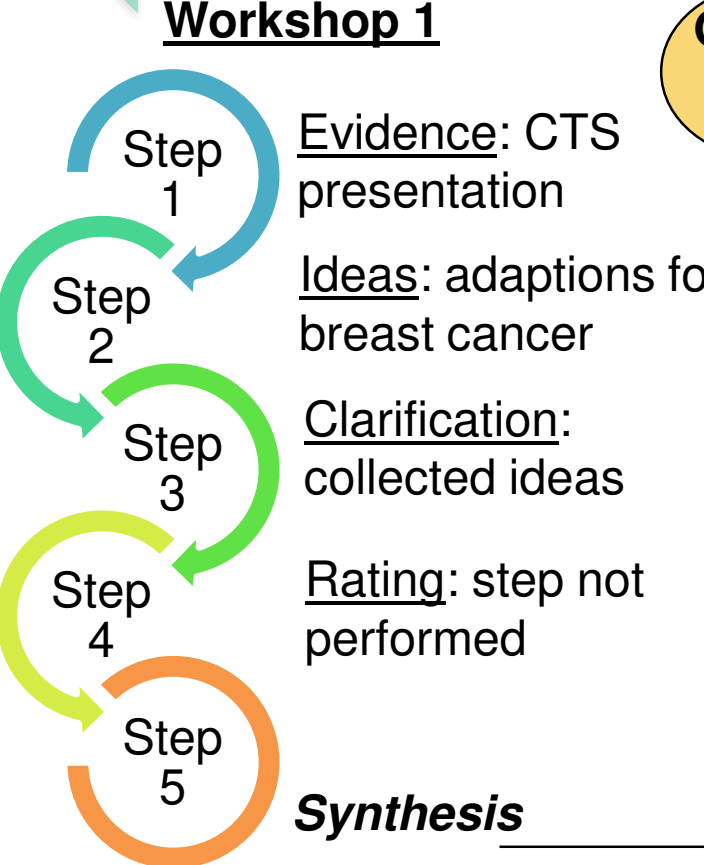

November 2016

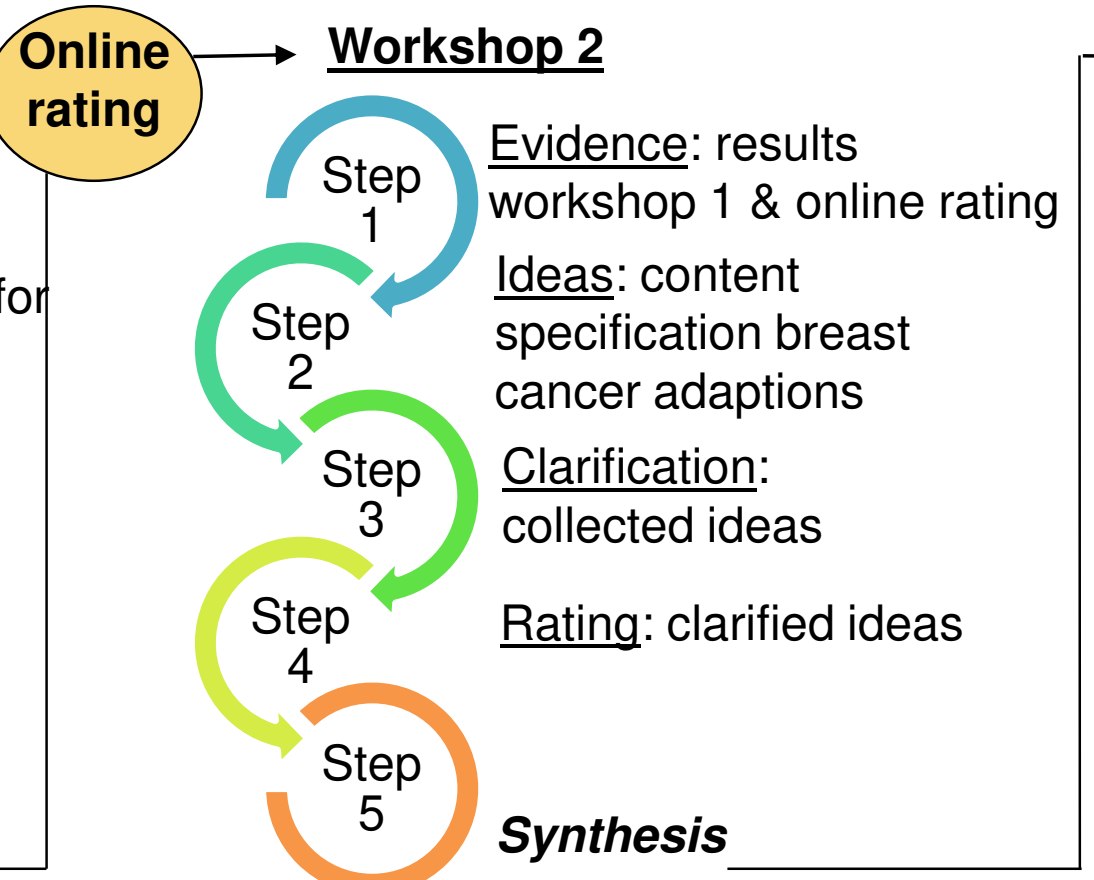

February 2017

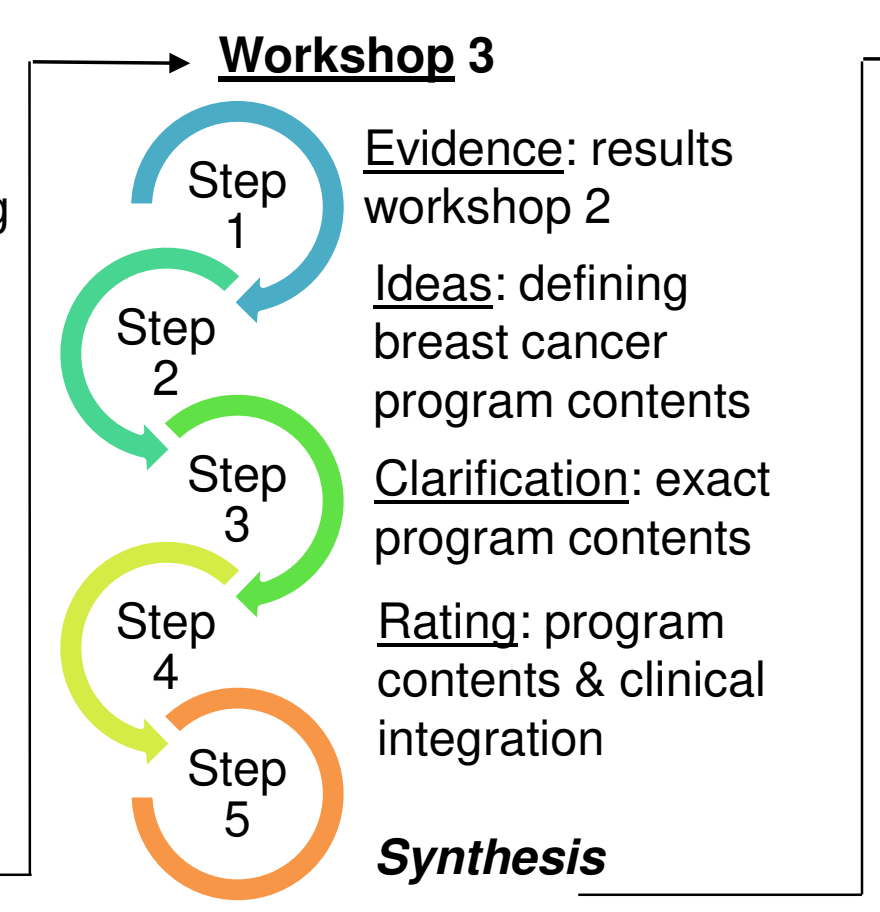

April 2017

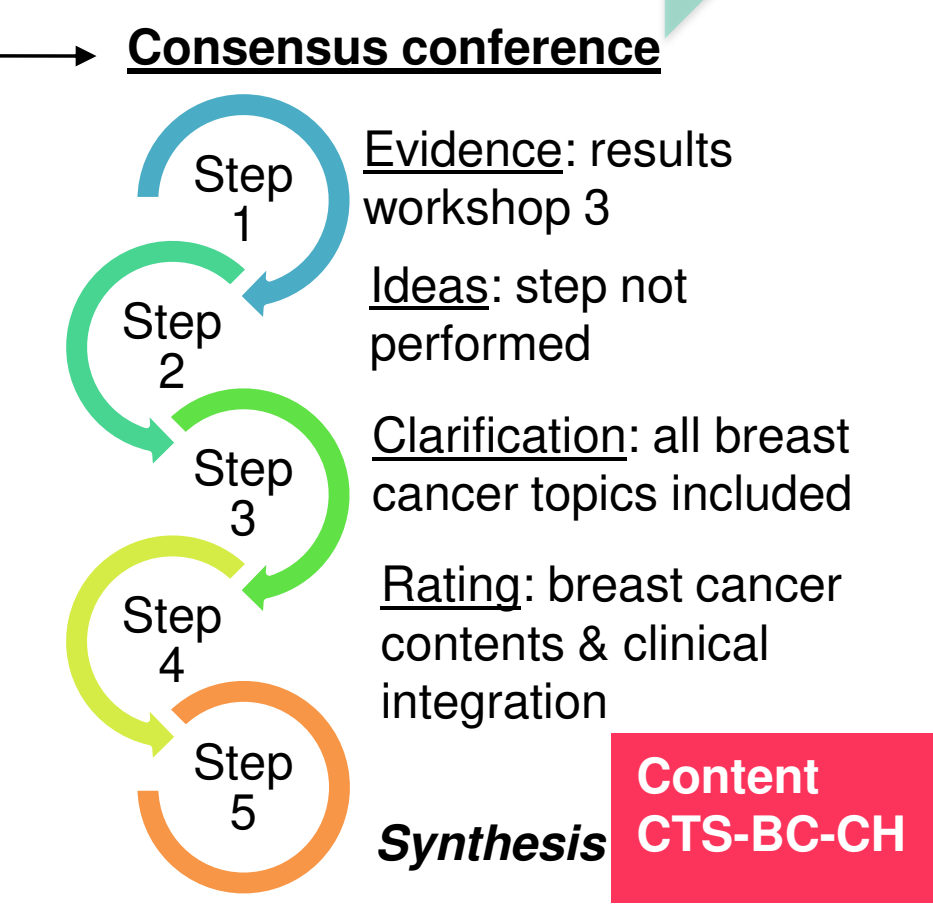

June 2017

- Three interdisciplinary workshops based on a participatory approach including active patient engagement helped to identify topics specific to breast cancer.

- Topics were confirmed by a national multi-stakeholder online rating.

- At a final consensus conference with international experts in the field of self-management and breast care, agreement on the program was reached $\rightarrow$ resulted in "The Cancer Thriving and Surviving Program for Breast Cancer Survivors in Switzerland $(\mathrm{CTS}-\mathrm{BC}-\mathrm{CH})$.

\section{Content CTS-BC-CH}

- The course was extended from 6 to 7 weeks (one 2-1/2 to 3 hours course per week).

- Course titles of existing modules were modified and partly retitled to better address the needs of breast cancer survivors: "Breast cancer and social relationships"

- New course titles \& contents were created specific to breast cancer: "My exercise", "Being a woman and having breast cancer", "My (working) life".

- New interactive activities were developed: "Take a stand" to help patients deal better with difficult questions and a new "role play" about how to say "No" were created.

\section{Integration clinical pathway:}

Best time point to introduce CTS-BC-CH in breast centers

$\rightarrow$ Transition from acute treatment to follow-up care.
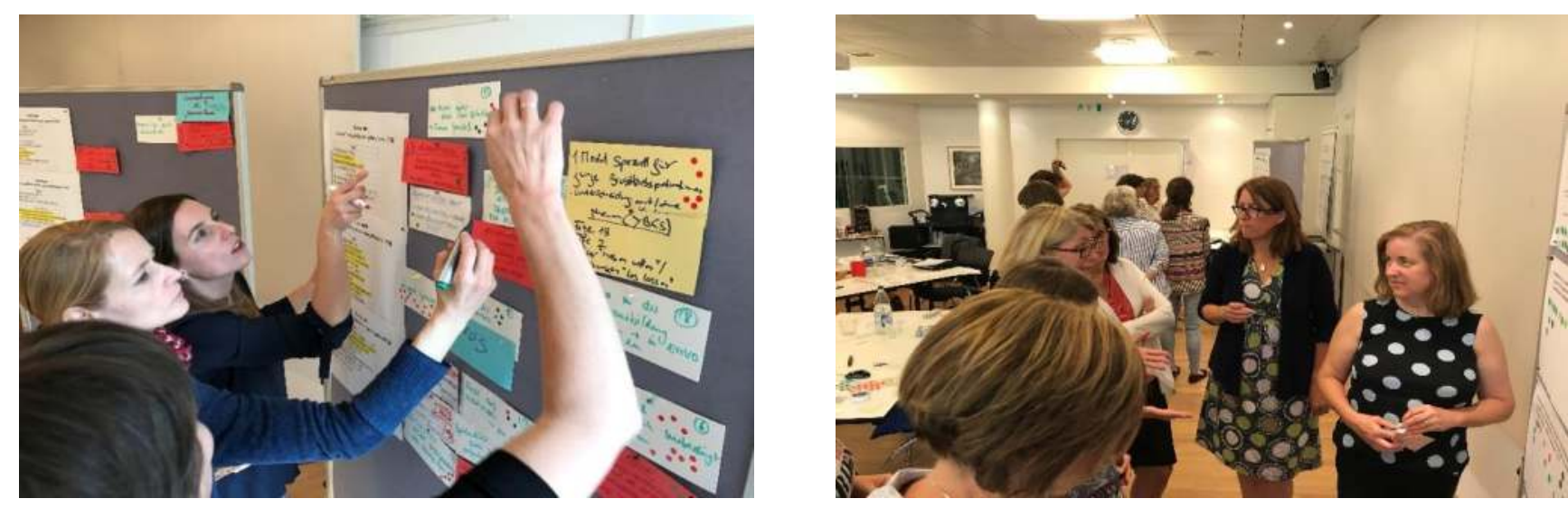

Photo 1 \& 2. Workshop \& consensus conference impressions
"Which of the following course contents do you consider to be so important that they should be included within the course activity "Living With Uncertainty" of a breast cancer-specific self-management program?"

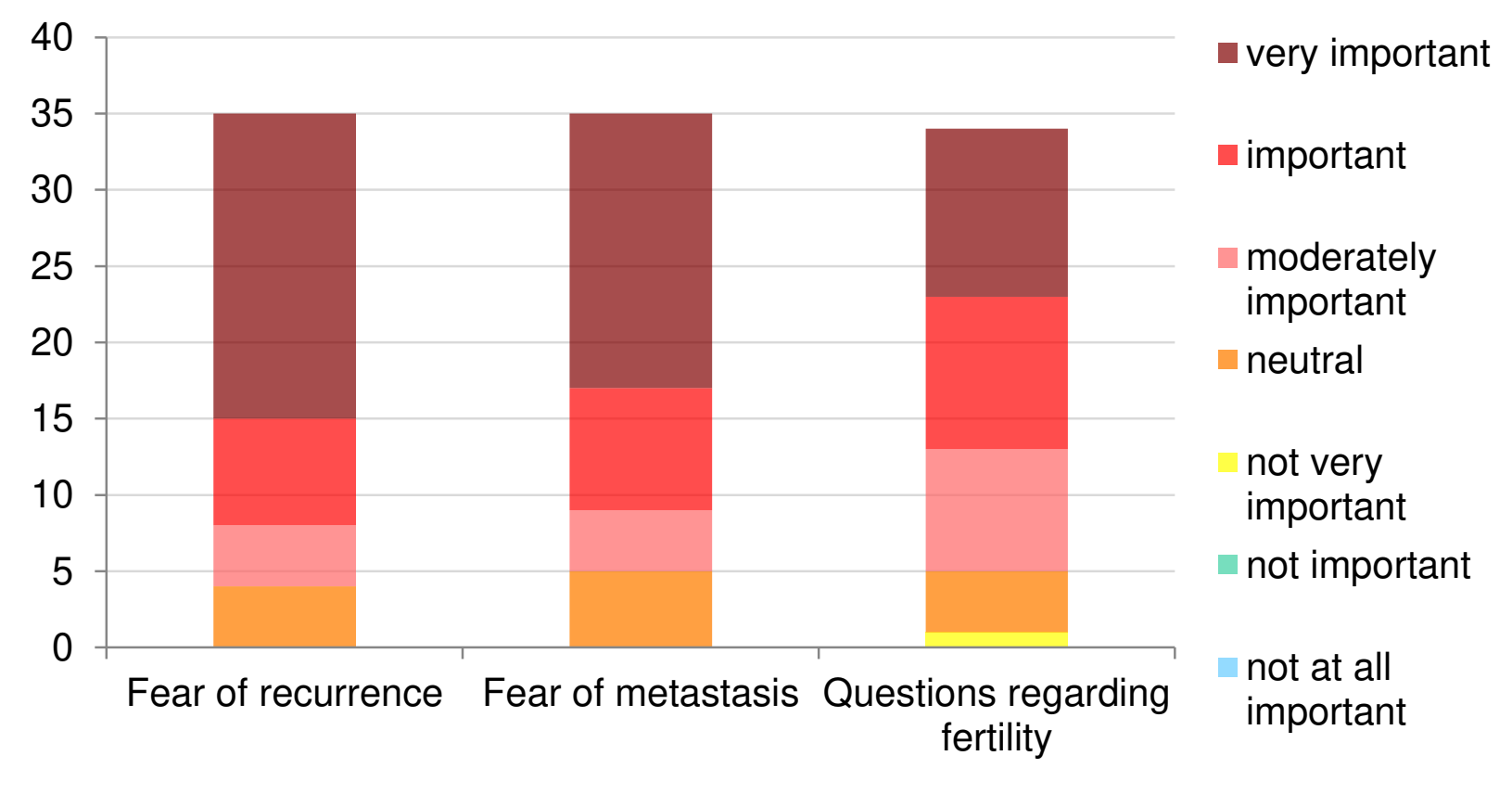

Figure 1. Result online rating

\section{CONGLUSIONS \& PERSPECTIVES}

- The CTS-BC-CH is now ready to be introduced into the clinical pathway of breast centers.

- Its feasibility and preliminary effectiveness will be tested in a pilot study compared to usual care with ongoing recruitment in two breast centers in Switzerland. 